\title{
The Role of the COVID-19 Pandemic in the Development of Remote Education in Universities in Russia
}

\author{
Vydrevich M. B.* Pervukhina, I. V. \\ Ural State University of Economics, Ekaterinburg 620144, Russia \\ *Corresponding author. Email: mbv@usue.ru
}

\begin{abstract}
This paper discusses the development of remote education in higher education institutions in Russia in the context of its modernization and digitalization. It is shown that the COVID-19 pandemic has forced the entire higher education system to switch to online education in the shortest time possible. At the same time, about $40 \%$ of universities have had the experience in developing remote education technologies since the 2000s. These technologies were not used for all students. They were used for the students who for some reason could not or did not want to educate in the traditional form. This group of universities was more or less ready for a difficult situation. The Russian higher education system as a whole has passed the stress test. As a result of the study, the strengths and weaknesses of the switch to remote learning in higher education institutions were revealed. Recommendations for improving and implementing online education in Russian universities are offered.
\end{abstract}

Keywords: higher education in Russia, remote learning in higher education, higher education system transformation, Covid-19 pandemic

\section{INTRODUCTION}

Currently, another transformation of industrial society is taking place. According to various authors, this happens due to the third [1] or fourth [2] industrial revolution. This transformation is characterized by widespread digitalization, telecommunications technologies explosive development and erasing the lines between physical and virtual reality. Changes in the life of society that are taking place at an increasing pace have caused serious changes in the education system, first of all, in the sphere of higher education.

These changes are associated with the following trends [3]: educational space globalization;

- changing the educational paradigm from knowledge-oriented to competence-based. Results became the main priority. The formation of necessary general cultural and professional competencies, self-determination, socialization, development of individuality and selfactualization became more important;

- implementation of the continuing education and self-education concept;

- the widespread introduction of information and telecommunication technologies in the universities educational process [4].

Classical University methods and forms of education are losing their effectiveness. In the innovative type of social development, situational knowledge becomes a priority and replace abstract fundamental knowledge.

Changing education priorities, especially in the higher education sphere, requires innovation in educational technologies. Introduction of the Internet at the end of the
XX — beginning of the XXI century and the state's course towards digitalization in all spheres of life led to the spread of remote education.

The main objective of the work is to analyze the situation with the use of remote education in higher education institutions of Russia, to identify its strengths and weaknesses, advantages and disadvantages, and to assess the role of the COVID-19 pandemic in the development of remote education.

\section{RESEARCH METHODS}

The following theoretical research methods are used in the paper: analysis and synthesis, comparison, specification and generalization.

The research methodology is based on a systematic approach that includes general scientific methods (deduction, induction, analysis and synthesis, comparison, specification and generalization, comparative analysis, etc.). The integrated research model based on an interdisciplinary approach that takes into account the mutual influence between the economic component (macrolevel) and the social response (micro-level) was also used.

\section{DEFINITION AND CHARACTERISTICS OF REMOTE EDUCATION}

Since the middle 1990s, numerous definitions of the term "remote education" have been given. In Russia, until recent time, "remote education" concept interpretation in scientific 
papers and official documents was controversial. And this is fully reflected in the work [5]. We believe that the most comprehensive definition is the one given in the late 1990s by the University Professors Association in a statement on remote education. This document defines remote education (or distance learning) as an education in which "Lecturer and student are separated geographically so that there is no face-to-face communication; instead, communication is carried out using one or more technical means, most often electronic (interactive television, satellite television, computers, etc.)" [6].

Three main concepts are common to all definitions of the term "remote education":

1. Education in which the course of study is conducted with the participation of both the lecturer and the student.

2. Barriers of place and/or time overcoming. Remote education was originally developed for lecturers and students who were not located in the same geographical region. Recently, remote learning can also serve those who may be in the same place but prefer not to meet at the same time.

3. Using a certain technology to communicate between a lecturer and a student. Currently, these are easily accessible electronic telecommunications technologies (audio, video, and information).

The main characteristic of remote education is its interactivity. All components of the educational process (lecturer, students, educational materials and teaching tools) constantly and systematically interact [7].

Advantages of remote education:

- $\quad$ it allows a student to educate without being at the University. It saves time and money. A flexible learning schedule allows working students to combine learning and completing the official duties;

the ability to flexibly manage educational programs at students' own option. Students can study educational material at the optimal time, in a convenient place that they choose themselves;

the ability to create a curriculum that meets the needs of a particular student. Students can study a set of independent courses and modules at their discretion;

- it allows implementing the basic principles of modern education: education for everybody and lifelong learning, including professional development, new qualifications, and non-formal courses.

- Disadvantages of remote education:

- $\quad$ it is impossible to study without special equipment and the Internet;

- the complexity of monitoring the students' learning process and students' attestation;

- $\quad$ it is impossible to fully learn the programs that require studying in real-world learning environments, especially when getting technical education;

- $\quad$ insufficient social interaction can make it difficult for a student to integrate into the social environment and successfully function in society;
- $\quad$ stigmatization of online learning: many employers are biased towards an education document obtained as a result of remote learning.

The popularity of remote education among students and lecturers in higher education institutions can be explained by its flexibility and availability at any time, regardless of geographical location.

There are three main models for organizing the educational process using remote technologies [8]:

1. Using the cases involves the transfer of an educational and methodological complex set to students in printed form. The printed materials, CDs, or a combination of both can be the storage media. The advantage of this model is the implementation speed and cost. This model is effective in comparison with other types of remote learning.

2. The use of broadcast technology is based on the use of global and local networks and television broadcasting for educational resources.

3. The network technology model is based on the use of a software tool installed on the university server. It allows students to learn and to monitor the received knowledge using the Internet. It can also be used for traditional educational forms.

With the help of remote learning technologies users should get the necessary material, students and lecturers should interact, students should have the ability to learn and practice the material themselves [9, p. 2]. Currently, the most extensive functionality of information technologies is provided by modern remote learning systems that allow users to create, store and deliver educational content and include learning management tools [9, p. 195].

The necessary conditions for the successfully functioning remote education in modern realities are:

- the presence of an interactive learning and information environment that can be constantly updated and adapted to the needs of the educational process. This means electronic and online sources of information, online consultations, etc.;

- the remote interaction between the lecturer and the student as one of the main and important factors in obtaining the knowledge system.

\section{THE INTRODUCTION OF REMOTE TECHNOLOGIES IN THE EDUCATIONAL PROCESS OF HIGHER EDUCATION INSTITUTIONS OF RUSSIA}

The introduction of remote learning technologies in the educational process of certain Russian universities began in the 1990s. At the same time, these technologies were used as a traditional form of education in relation to students who, for some reason, could not or did not want to educate in the traditional form. Currently, remote education in the Russian Federation is regulated by the Federal law "On education in the Russian Federation" (article 16) [10] and departmental regulations in the field of e-learning and remote education technologies $[11,12,13]$. 
At the initial stage, the remote education technological base was only electronic textbooks, audio and video lecture courses and communication tools designed for students to study and practice the educational material and send the completed tasks independently. The use of modern telecommunication means and technologies has made it possible to make remote learning more like face-to-face learning.

Russia does not hasten to apply remote education. The main reasons are:

- $\quad$ there are not enough places that can withstand the mass switch to remote learning, the quality of services provided by the most popular free services is inadequate, the mechanism for fee-paying digital resources is not centralized;

- $\quad$ remote education technologies are mainly used as a form of organizing the educational process, rather than receiving education. The quality of such educational services is low:

- the potential remote learning consumers are not sufficiently informed about its advantages. $21 \%$ of respondents consider remote education convenient and of high-quality, $45 \%$ are convinced that its quality is lower than the quality of face-to-face education and $34 \%$ have no idea about it [14].

Russian universities are highly differentiated in terms of their financial capabilities, quality of education and teaching staff. It is reflected during the introduction of remote education technologies. If the situation does not change, then, according to the Agency for Strategic Initiatives under the Russian Federation Administration forecasts, by 2025, the country's universities will differentiate into:

leaders providing unique content for mass open online courses (MOOCs);

"middles" or those who produce their own educational content and use MOOCs from other universities; Underperforming universities or those who perform learning using the MOOCs from outside providers [5].

\section{RUSSIAN HIGHER EDUCATION IN THE CONTEXT OF THE PANDEMIC}

The pandemic caused by the COVID-19 virus led to the need to isolate lecturers and students. The country's universities should not stop the educational process. Universities had to mobilize all resources for a comprehensive solution to the problems of switching to remote learning. According to the rectors of leading Russian universities, the higher education system has coped with the stress test of the coronavirus pandemic [15]. In the third decade of March 2020, more than $80 \%$ of higher education institutions were able to organize online learning to some extent. The cases of complete suspension of learning are not common. The learning process was transformed and gained a hybrid form. In-class learning was replaced by video broadcasts, lectures were held in the format of webinars, and the educational process interactivity was increased. Mixed-type training using external courses and products has become a mass phenomenon. About a third $(28 \%)$ of educational programs are partially or fully implemented using online platforms [16]. The most popular open platform resource is the national platform "Open education" [17]. This indicates that the infrastructure solutions for the online education development laid in recent years have appeared to be relevant in a critical situation.

But the critical situation revealed a number of significant problems. The switch of the usual education forms into a digital environment required special skills not only from lecturers. They should be familiar with digital solutions, a new format of interaction with students, etc. Students had to have some special skills like putting the additional efforts to self-organize, self-orientate in information flows, etc. Moreover, universities had to be prepared. The administration, lecturers and students were not ready to work in a "remote environment" not only because they were not ready for digital transformation as such, but also because of the dynamics of the changes in established processes [16Ошибка! Закладка не определена.]. In the first two weeks of the quarantine, $44 \%$ of universities were unable to mass-organize simultaneous remote learning. Only $20 \%$ of higher education institutions were able to maintain learning in simultaneous mode, while the switch of the rest to the remote learning led to a partial $(60 \%)$ or complete loss of the education quality (20\%).

Universities that developed remote learning practised independent work, student projects, and course selection were able to adapt to the new reality and survive quarantine measures without significant losses. They had time-tested remote learning technologies, experience in working with students remotely, appropriate equipment and software, methodological projects for conducting online classes, and training materials for remote learning. Most of the lecturers in these universities had experience in conducting classes in a remote form. But there are no more than $40 \%$ of such higher education institutions in the country [18]. The rest of higher education institutions had to gain experience in distance learning "on the fly". About $40 \%$ of Russian universities were unable to provide students with remote access to educational resources, and $70 \%$ of lecturers of these educational institutions did not know how to organize work with the remote communication [19].

Many universities do not have sufficient infrastructure to implement remote or mixed learning. The number of universities that have a sufficient digital infrastructure to fully organize online learning and post content on their own resources does not exceed $11 \%$. In $15 \%$ of universities, the lack of electronic communication with students led to the fact that some students were either insufficiently informed about the new requirements or simply did not receive the information [15Ошибка! Закладка не определена.]

The lecturers' problems during the switch to remote learning are associated with insufficient competence and psychological discomfort. This problem is caused by a large number of lecturers in the $65+$ age category $(20 \%)$, lack of experience in remote learning $(60 \%)$, sceptical attitude to remote learning $(88 \%)$, and lack of competence in the field 
of digital and telecommunications technologies (20\%). The significant part of higher school lecturers lacks the necessary competencies, especially the older ones, of in the field of new information and communication technologies and modern methods of distance learning. And this turned out to be an extremely painful problem. Two months after the quarantine, only $36 \%$ of them were able to get the necessary skills. However, the experience of working remotely led to an increase in the number of lecturers (from 30 to $70 \%$ ), who saw new opportunities for using remote education technologies to increase the quality education availability.

Another problem is the diversity of the students' financial situation. It threatens equal opportunities for continuing remote learning. More than $10 \%$ of students do not have the equipment that meets all functional requirements. Moreover, they do not have the ability to improve the situation. The lack of facilities for training also reduces the chances of successful completion of disciplines. $28 \%$ of students say that it is difficult for them to study at home.

\section{REMOTE EDUCATION PROBLEM ASPECTS}

The switch to a digital environment involves not just transferring the existing educational process to another environment. It also requires the implementation and development of new digital teaching methods. The lecturers should find completely new ways to maintain students' motivation, individualization, interactivity and involvement.

Converting a traditional course to online course is a creative and time-consuming job. For the effective use of remote learning technologies, lecturers have to:

- develop a remote learning course based on available sources of information and their own materials. They should use a learning management system (LMS);

- have the skills to manage students' cognitive activity in simultaneous and asynchronous modes. The remote learning technologies specifics should be taken into account;

- develop adequate assessment tools for monitoring the educational results and academic performance.

A prerequisite for completing this task is professional knowledge of technologies for developing digital educational content and its application in the educational process.

- $\quad$ The lack of lecturers' readiness for remote learning appears in the following:

lectures and other educational materials for selfstudy are laid out without additional explanations of the most difficult points. This increases the students' work significantly given that they rarely have access to the necessary literature;

- universities do not have technologies for real-time monitoring of the students' assignments quality, including the end-of-course assessments (methods for evaluating learning results).
Lack of readiness for the effective use of innovative technologies and increased labour intensity form negative attitudes towards online learning formats from some lecturers' point of view. This reflected in online formats that were almost not affected by working remotely [15].

The remote education creates a high risk of social isolation. One in four respondents noted that they feel lonely and isolated. More than $40 \%$ of students recognize the lack of communication with their classmates and personal conversations with teachers as a serious problem. The indirect interaction between students and the lecturer does not sufficiently contribute to the formation of socially accepted values, rules and norms of behaviour among students, so it is necessary to update the pedagogical function of learning [20].

In the conditions of remote education, the probability of falsification increases and the problem of controlling the educational process at a distance arises. The proven and successfully practised remote form of passing tests and exams is an integral part of remote learning. This problem can be solved using special technical tools and techniques, for example, using a messenger such as Skype or special university software. The need to conduct tests and exams remotely and verify their results has led to the active introduction of proctoring technologies by universities. In Russia, for example, "Examus" online proctoring is used in universities. It includes a preliminary procedure for verifying the identity of students with the use of biometric data, video surveillance throughout the exam, and video recording of the test or exam. The latter can be used if the student does not agree with the test result. Unfortunately, there is almost no competition in the Russian market among suppliers of such services and the available ones are extremely expensive.

Education in natural sciences, medicine, or creative professions cannot be fully carried out in a remote format. The development of virtual reality technologies that create the effect of virtual presence of the lecturer and student in the simulated situation (laboratory work, object research, etc.) can hardly help solving this problem in full [5].

Thus, remote learning technologies are an effective tool for teaching, but their effectiveness increases if they are integrated with traditional educational forms. The experience of the Ural State University of Economics shows that remote learning should not exceed $40 \%$ of the total number of study hours for economic and humanitarian education [18]. For other areas of learning (technical, medical), the proportion may be different.

\section{CONCLUSION}

Remote education development and improving the technologies that meet national and international quality standards are important elements of modernizing the Russian higher education system. A university that considers universal access to education its top priority should consider remote learning as a key element of its mission. 
The remote learning technologies are an effective tool for teaching students, but their effectiveness increases when integrating with traditional educational forms. The experience of the Ural State University of Economics shows that for economic and humanitarian education, distance learning should not exceed $40 \%$ of the total number of academic hours. For other specialties, the proportion may be different.

The pandemic caused by the COVID-19 virus and the associated need to switch to remote learning format showed that the Russian higher education system has coped with the stress test of the coronavirus pandemic.

The main problems of remote higher education development in Russia are related to

the lack of necessary lecturers' qualifications, especially the older ones, in the field of new information and communication technologies and modern methods of remote learning, as well as negative attitudes of a certain part of lecturers towards online learning formats associated with the increased labour intensity and lack of lecturers' readiness to use new technologies effectively;

- lack of a remote learning environment aimed at adapting students to remote learning;

- limited universities technological and financial capabilities;

- the lack of a unified educational standard for remote education, which would allow unifying the technology and methodology of remote education, mechanisms for real-time quality students' performance control, including final attestations.

- $\quad$ To solve these problems, it is necessary

- $\quad$ to create a unified remote education standard (a set of methods and rules for teaching online) and digital teaching methods;

- to prepare higher education institutions to integrate information and communication technologies;

- $\quad$ to create an adaptive remote learning environment that will allow lecturers to teach online effectively, and students to educate effectively;

- $\quad$ to create a system of lecturers' mass retraining in the fields of information and communication and remote education technologies, to create a system of lecturers' motivation to use digital resources, to form the ideas, not about the complete switch to online education, but about the introduction of technology elements that will facilitate the work;

to ensure the information security of the structure, technologies and components of remote learning.

- The changes in the Russian higher education system related to the pandemic are expected to trigger the spread of remote education in the country's universities in the post-crisis period, which will greatly contribute to the digitalization of all spheres of life.

\section{REFERENCES}

[1] J. Rifkin The Third Industrial Revolution: How Lateral Power Is Transforming Energy, the Economy, and the World, New York, Palgrave Macmillan. 2011. ISBN 13-9780230115217.

[2] K. Schwab, The Fourth Industrial Revolution, New York, Crown Business, 2017.

[3] A.A. Zyablov, G.A. Afanasyeva, A.V. Egorova, Problems of Transformation of The Russian Higher Education System in the Conditions of Transition to the Digital Economy, Ecology of urban areas 4 (2018) 104 106. DOI: $10.24411 / 1816-1863-2018-14104$

[4] S. D. Kalinina, MGIMO Review of International Relations., MGIMO Review of International Relations 2(41) (2015) 291-295.

[5] I A Kislukhina, The use of distance learning technologies in the system of higher education: problems and prospects, Economic Systems Management: electronic scientific journal 9(103) (2017) 7.

[6] Statement on Online and Distance Education, in: report "Distance Learning," Academe: Bulletin of the AAUP 84 (1998) 30-38.

[7] O. Bondareva, A. Tenea, Kh. Ismailova, To the question about the concept of «Distance learning», Norwegian Journal of Development of the International Science, 14-2 (2018) 40-41.

[8] M.E. Weindorf-Sysoeva, V.A. Shitova, On the models of using distance educational technologies in a modern university, Bulletin of the Moscow State University for the Humanities M.A. Sholokhov. Ser. Pedagogy and Psychology 4 (2013) 29-34.

[9] M.B. Lebedeva, S.V. Agaponov, M.A. Goryunova et al., Distance educational technologies: design and implementation of training courses, St. Petersburg, BHV Petersburg, 2010.

[10] Federal Law "On Education in the Russian Federation" of December 29, 2012 N 273-FZ (as amended on April 24, 2020).

[11] On the approval of the Procedure for the application of e-learning, distance educational technologies by organizations carrying out educational activities in the implementation of educational programs, Order of the Ministry of Education and Science of the Russian Federation of 23.08.2017 No. 816.

[12] Guidelines for the use of e-learning, distance learning technologies in the implementation of 
additional professional educational programs, Appendix to the letter of the Ministry of Education and Science of the Russian Federation of April 10, 2014 N 06-381.

[13] On the approval of the lists of professions and specialties of secondary vocational education, the implementation of educational programs for which is not allowed using exclusively e-learning, distance learning technologies (as amended on December 10, 2014), Order of the Ministry of Education and Science of the Russian Federation dated December 10, 2014 year N 1564 .

[14] Pros and cons of distance education, in: Information site "My education".

https://moeobrazovanie.ru/plusy_i_minusy_distancionn ogo_obrazova-niya.html

[15] Lessons from the "stress test". Universities in a pandemic and after it, Analytical report. URL:

http://fgosvo.ru/uploadfiles/lesson_stress_test.pdf

[16] A.V. Klyagin, E.S. Abalmasova, K.V. Garev et al., The storm of the first weeks: how higher education stepped into the reality of a pandemic, National Research University Higher School of Economics, Institute of Education. - M .: NRU HSE, Modern Education Analytics 6 (36)), 2020.

[17] National Platform "Open Education". https://openedu.ru

[18] M. Maramygin, Interview "The experience we have received is simply grand," Kommersant (Yekaterinburg).

https://www.kommersant.ru/doc/4399095?from=doc_vr ez

[19] N.N. Oleinikov, Formation of skills in the use of elements of distance learning technologies among teachers of higher education, New Science:

Psychological and Pedagogical Approach 2 (2017) 136138.

[20] E.V. Romanov, T.V. Drozdova, Distance Learning: Necessary and Sufficient Conditions for Effective Implementation, Modern Education 1 (2017). 172-195. DOI: 10.7256 / 2409-8736.2017.1.22044. 